\title{
Molecular heterogeneity of the cerebriform connective tissue nevus in mosaic overgrowth syndromes
}

\author{
Kim M. Keppler-Noreuil, ${ }^{1,3}$ Jasmine Burton-Akright, ${ }^{1}$ Marjorie J. Lindhurst, ${ }^{1}$ \\ Jasmine Shwetar, ${ }^{1}$ Julie C. Sapp, ${ }^{1}$ Thomas Darling, ${ }^{2}$ and Leslie G. Biesecker ${ }^{1}$ \\ ${ }^{1}$ National Human Genome Research Institute, National Institutes of Health, Bethesda, Maryland 20892, USA; \\ ${ }^{2}$ Department of Dermatology, Uniformed Services University of Health Sciences, Bethesda, Maryland \\ 20814, USA
}

\begin{abstract}
The clinical diagnostic criteria for Proteus syndrome were defined before the discovery of the AKT1 c.49G >A; p.(Glu17Lys) causal variant and used a combination of general and specific phenotypic attributes that could be combined to make a clinical diagnosis. The most heavily weighted specific criterion was the cerebriform connective tissue nevus (CCTN). Here, we describe two individuals with connective tissue nevi (CTNs) and some general attributes of Proteus syndrome who were found to have mosaic PIK3CA variants. CTNs on the soles of individuals with PIK3CA-related overgrowth typically exhibit thickening of the soft tissues with at most a wrinkled surface, but these two patients had firm plaques with ridges and furrows characteristic of CCTNs, which was histologically confirmed in one. These data show that CCTNs are not specific to Proteus syndrome and that clinicians should be cautious in diagnosing individuals with Proteus syndrome based on the CCTN alone. Rather, a complete evaluation should include careful assessment of other attributes of the diagnostic criteria and, whenever possible, genetic analysis of affected tissue.
\end{abstract}

Corresponding author: lesb@mail.nih.gov

This is a work of the US Government.

Ontology terms: connective tissue nevi; overgrowth

Published by Cold Spring Harbor Laboratory Press

doi:10.1101/mcs.a004036

\section{INTRODUCTION}

The clinical diagnosis of Proteus syndrome is established by a set of clinical criteria that were first delineated in an $\mathrm{NIH}$ workshop in 1998 and published the next year (Biesecker et al. 1999). These criteria were slightly modified several years later (Biesecker 2006). The criteria were created and implemented before the molecular discovery of the cause of Proteus syndrome (Lindhurst et al. 2011) and PIK3CA-related overgrowth spectrum (PROS) (for review, see Keppler-Noreuil et al. 2015). The Proteus clinical criteria worked well as there was a high correlation of meeting the clinical criteria and being found to be mosaic for the c.49G $>A$ AKT1 variant (Lindhurst et al. 2011).

These clinical criteria require evidence of three mandatory general attributes-sporadic occurrence, mosaic distribution of lesions, and progressive course. These must be accompanied by one or more specific criteria, several of which comprise skin findings (Table 1). The cerebriform connective tissue nevus (CCTN) is one of the most characteristic skin lesions. It commonly occurs on the soles of the feet and has significant associated morbidities (Beachkofsky et al. 2010). The CCTN was thought to be highly predictive for Proteus syndrome so it was the only specific criterion that could support the clinical diagnosis (again,

\footnotetext{
${ }^{3}$ Present address: Children's National Medical Center, Washington, D.C. 20001, USA
} 


\begin{tabular}{lll}
\hline Table 1. Proteus syndrome diagnostic criteria in two individuals & & \\
\hline Proteus syndrome diagnostic criteria & & \\
a & $\begin{array}{c}\text { Individual } \\
\text { OG194 }\end{array}$ & $\begin{array}{c}\text { Individual } \\
\text { OG111 }\end{array}$ \\
\hline Mosaic distribution of lesions & Yes & Yes \\
Sporadic occurrence & Yes & Yes \\
Progressive course & Minimal & Minimal $^{\text {b }}$ \\
(A) Cerebriform connective tissue nevus & Yes & Yes \\
(B) Linear epidermal nevus & No & No \\
(B) Asymmetric, disproportionate overgrowth & Minimal ${ }^{\mathrm{b}}$ & Minimal \\
(B) Bilateral ovarian cystadenoma or parotid monomorphic adenoma & No & No \\
before second decade & & \\
(C) Dysregulated adipose tissue & Yes & No \\
(C) Vascular malformations & No & No \\
(C) Bullous lung disease & No & No \\
(C) Facial phenotype & No & No \\
\hline
\end{tabular}

${ }^{a}$ Diagnosis requires all three general criteria AND either one from (A), two from (B), or three from (C).

${ }^{\text {b}}$ The history for progressive overgrowth was minimal in that they had some progressive overgrowth as an infant/toddler but little or none in the subsequent decades, which is quite different from the typical overgrowth of Proteus syndrome.

as long as the general criteria were met). Here we report two individuals with the diagnosis of PROS with characteristic clinical features confirmed by the presence of a somatic pathogenic variant in PIK3CA, who both presented with CCTNs on the sole of their affected, overgrown foot. We review the diagnosis in these individuals, which has implications for clinical-molecular diagnosis of mosaic overgrowth disorders.

\section{Clinical Reports}

Individual 1 (OG.194) was a young adult female who presented at birth with enlargement of her left lower leg and foot, including toes two through four. She had progressive growth, especially of her toes, and had amputation of the left second to fourth toes at age 8 mo. She had overgrowth of the legs and feet subsequently, but this was modest, consisting mostly of some increase in the width of her left foot. She had a soft tissue overgrowth on the plantar surface of her left foot, which intermittently became dry and calloused with occasional bleeding. She had been noted to have mixed hyper- and hypopigmented macules on her trunk, but no vascular malformations. Her early developmental milestones were normal, and she had apparently normal intelligence with no neurologic abnormalities. Her general health was good.

On physical examination at $18 \mathrm{yr}$ of age, her height was $154.1 \mathrm{~cm}$ (10th centile), her weight was $49.1 \mathrm{~kg}$ (10th-25th centile), and her occipital frontal circumference was $55 \mathrm{~cm}$ (50th centile). She had overgrowth (increased girth and length) of the left lower leg, foot, and fifth toes with absent left second to fourth toes. The left and right measurements were as follows: length of lower legs (from posterior knee flexion crease to medial malleolus) $30.2 \mathrm{~cm}, 28.4 \mathrm{~cm}$; midfoot circumference $26.8 \mathrm{~cm}, 21.3 \mathrm{~cm}$; foot length $22.6 \mathrm{~cm}, 22.3 \mathrm{~cm}$; ankle circumference $25.4 \mathrm{~cm}, 22.7 \mathrm{~cm}$; fifth toe length $3.5 \mathrm{~cm}, 2.5 \mathrm{~cm}$ and circumference $8.5 \mathrm{~cm}, 5.1 \mathrm{~cm}$. The large plaque on her sole was notable for a ballooning appearance involving the forefoot and a cerebriform pattern medially and laterally (Fig. 1A-C). Radiographs (AP and lateral views) of her left foot demonstrated widening of the second to fourth metatarsal heads and shafts and calcific enthesopathy of the insertion of the Achilles' tendon and plantar fascia (Fig. 2A,B). Other skin findings included a $4.0 \times 5.0-\mathrm{cm}$ 


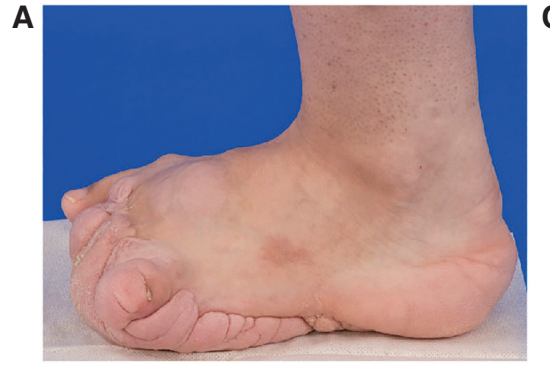

B

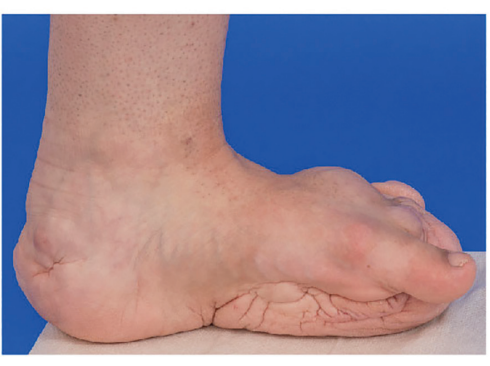

Figure 1. Individual 1 (OG.194). Left foot and ankle overgrowth with cerebriform connective tissue nevus (CCTN) on the sole of the foot. (A) Left foot, lateral view showed soft tissue overgrowth on the dorsal foot and CCTN on the sole of the foot. Toes two through four are absent status postamputation. (B) Left foot, medial view showed additional CCTN involvement of the heel. (C) Plantar and medial surfaces views demonstrated the cerebriform character of the connective tissue nevus with deep sulci and gyri.

hypopigmented macule on the upper left buttock, a few scattered uniformly brown melanocytic nevi on the bilateral arms, and irregular hyperpigmented and hypopigmented macules on her back.

Hematoxylin and eosin (H\&E)-stained sections of a 4-mm punch biopsy of skin from the left lateral foot showed thick bands of collagen oriented perpendicular to the surface (Fig. 3A,B), characteristic of collagenomas reported in Proteus syndrome (McCuaig et al. 2012). The elastic tissue stain showed absent elastic tissue displaced by thick bundles of collagen (Fig. 3C). Trichrome stain confirmed the abundant, abnormal collagen fiber bundles (Fig. 3D). Colloidal iron staining showed normal distribution of mucin.

Individual 2 (OG.111) was an almost 35-yr-old man, who presented with an enlarged right second toe at birth, and one small brown macule on his left knee. He had progressive overgrowth of that toe, resulting first in amputation of the distal phalanx at 10 mo of age, followed by amputation of the entire toe at $11 \mathrm{yr}$ of age. He had no discernible skeletal overgrowth subsequently. At $11 \mathrm{yr}$ of age, he also had excision of a benign lesion described as a vascular tumor on his left fifth finger and development of a CCTN on the sole of his right foot, which progressively increased in size in his teens and early $20 \mathrm{~s}$. He developed a second CCTN on his right great toe at age $22 \mathrm{yr}$. He participated in athletic activities (running and football) but had intermittent pain in the connective tissue nevus and his first and third toes. At $32 \mathrm{yr}$ of age, he was referred for the possible diagnosis of Proteus syndrome. Screening evaluations included an audiogram which showed bilateral low-frequency sensorineural hearing loss. His family history was positive for hearing loss in his otherwise unaffected sister. He had abdominal ultrasound findings of diffuse increased liver echogenicity and probably hepatic steatosis, and fasting blood work showed elevated cholesterol and triglycerides. Testicular ultrasound showed possible calcifications in the testes bilaterally and tiny cysts in of the epididymides.

On physical examination at $32 \mathrm{yr}$ of age, his height was $181.8 \mathrm{~cm}$ (75th centile), weight was $87.7 \mathrm{~kg}$ (80th-90th centile), and his OFC was $57.3 \mathrm{~cm}$ (75th centile). He had a skin- 

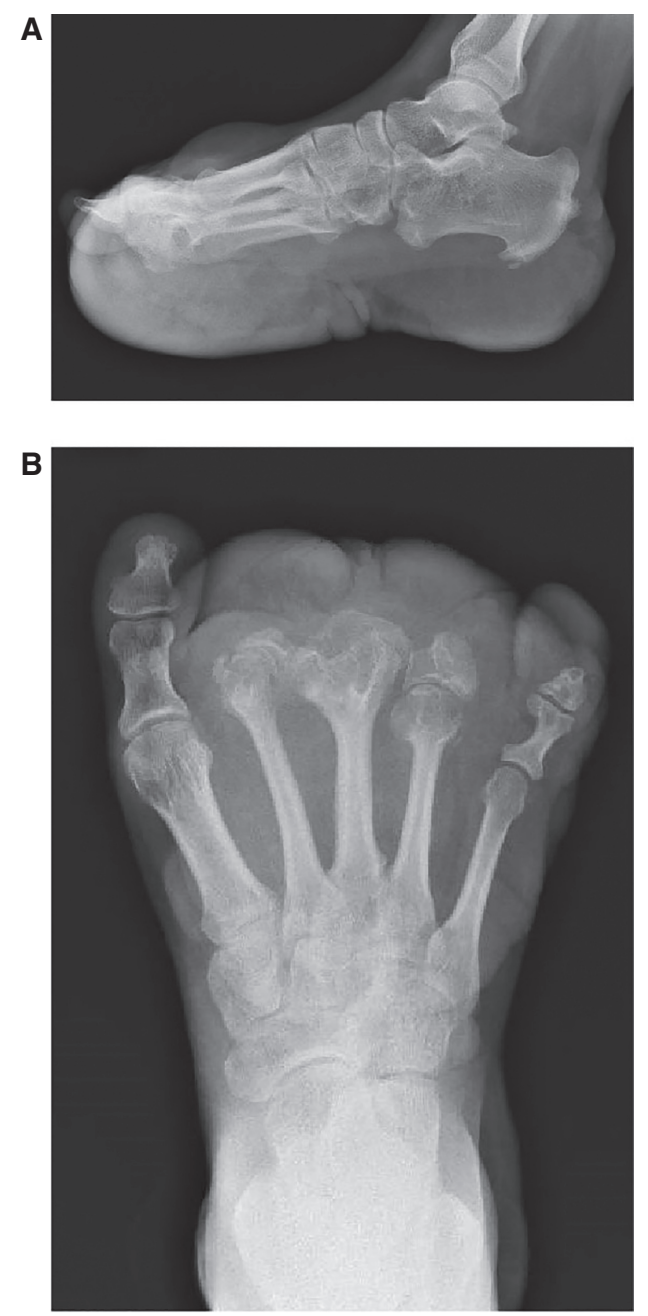

Figure 2. Individual 1 (OG.194). (A) Lateral and (B) AP radiographs of her left foot demonstrated partially absent second, third, and fourth phalanges, widening of the second to fourth metatarsal heads and shafts, calcific enthesopathy of the insertion of Achilles' tendon and plantar fascia, and prominence of plantar, midfoot dorsal soft tissue.

colored nodule, $1 \mathrm{~cm}$ in diameter on the front of his hairline. Most of his other abnormalities on examination involved the feet, with right hallux valgus, his right third toe had contracture at the PIP joint with a hammertoe, a CCTN on the plantar surface of the right foot, covering two-thirds of the foot from the midfoot to the toes, and in between the first and third toes measuring $12.5 \times 7.5 \mathrm{~cm}$, with a calloused area on the CCTN measuring $3 \times 2.3 \mathrm{~cm}$. On his right first toe, he had another CCTN, measuring $2.4 \mathrm{~cm}$ wide $\times 2.0 \mathrm{~cm}$ long. His right first toe was broad and at the base, the circumference was $5 \mathrm{~cm}$ (Fig. 4A,B). Radiographs of his right foot (AP and lateral views) showed absent second toe and metatarsal (Fig. 5A,B).

\section{Genomic Analyses}

Genomic testing on fibroblasts grown from two skin biopsies of the left foot of individual OG194 identified the PIK3CA c.3140A >G p.(His1047Arg) variant with variant allele fractions (VAF) of 0.11 and 0.34 (Table 2). The AKT1 c.49G>A variant was not detected. 
COLD SPRING HARBOR Molecular Case Studies

PIK3CA and cerebriform connective tissue nevus

A

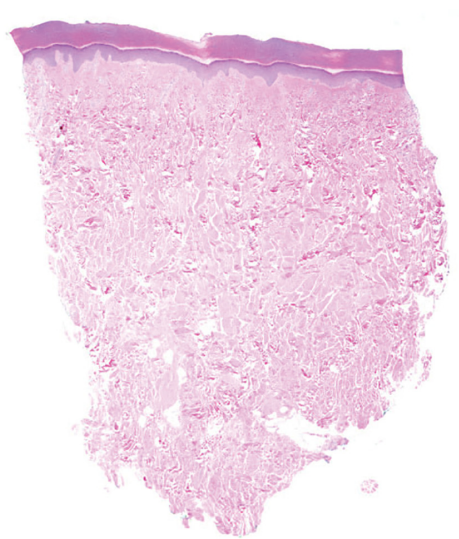

C

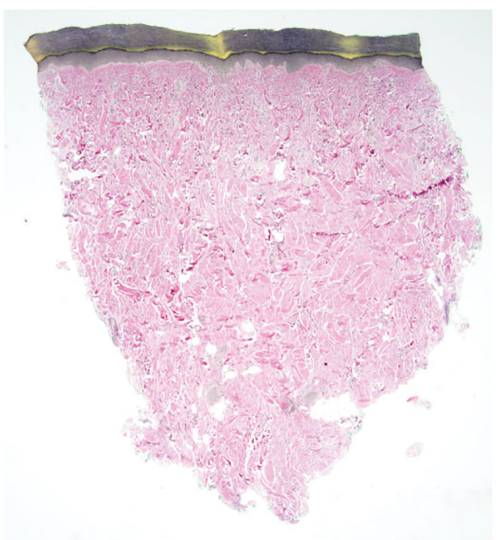

B

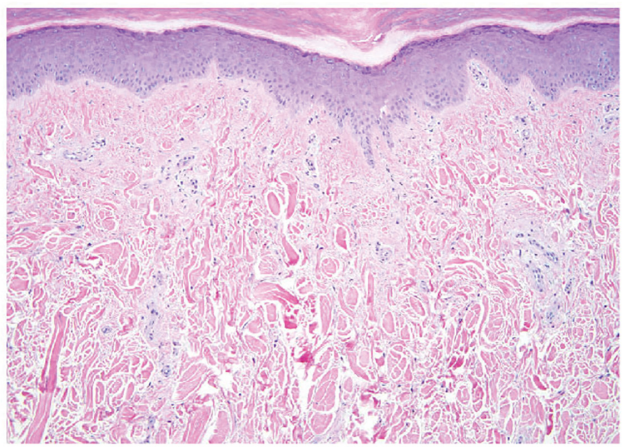

D

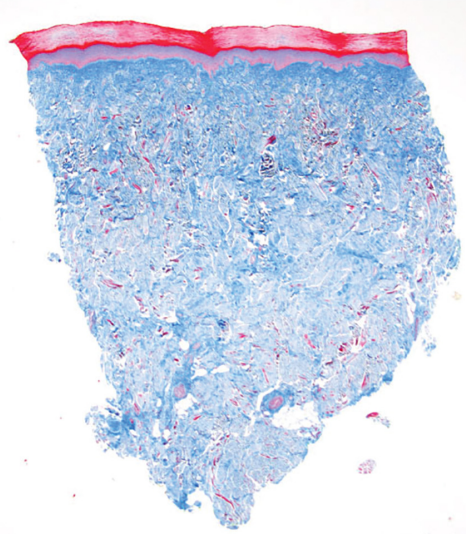

Figure 3. Histopathology of the connective tissue nevus on the left foot of individual 1 (OG.194). (A) $2 \times$ H\&E staining showing the overall architecture of the CCTN histology. (B) 10× H\&E staining confirmed there were primarily coarse bands of collagen and decreased elastic fibers. The thick bundles of collagen are oriented perpendicular to the surface of the reticular tissue. (C) $2 \times$ elastic tissue stain showed absent elastic tissue (black staining) displaced by thick bundles of collagen. (D) $2 \times$ immunohistochemistry staining of trichrome (blue staining) showed abundant, abnormal collagen fiber bundles.

Genomic testing of fibroblasts grown from each of the skin biopsies of the right foot instep of individual OG111 identified the mosaic PIK3CA c.3140A>G p.(His1047Arg) variant, with VAFs of 0.096 and 0.19 (Table 2). The AKT1 c.49G >A variant was not detected.

\section{DISCUSSION}

The CTNs were classified by Uitto et al. (1980), and this was refined by McCuaig et al. (2012). CTNs are hamartomas of the skin that can be subdivided based on the predominant component of the extracellular material that they comprise. CTNs that are of the collagen type are often referred to as collagenomas, but this is inconsistent in the literature. CTN of the collagen type were subdivided into seven types by McCuaig et al. to which we have added the entity described here (Table 3).

Histological features of a collagenoma include accumulation of dense and coarse collagen fibers with a relative paucity of elastic fibers in the dermis. It has been suggested that the CTN of Proteus syndrome has a specific histologic character of increased collagen fibers 


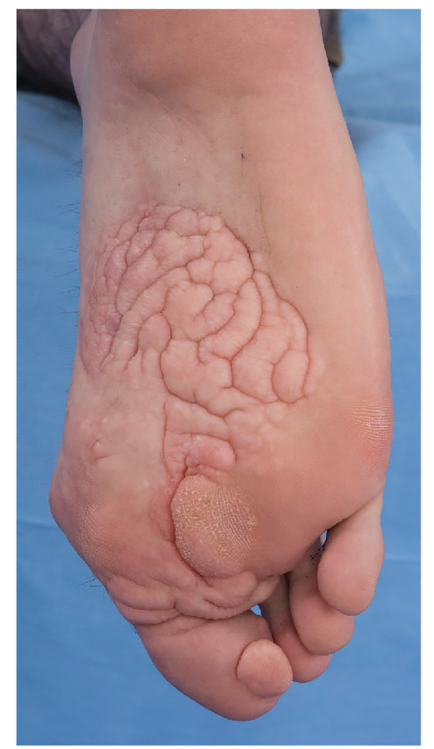

Figure 4. Individual 2 (OG.111). Right foot, plantar view showed cerebriform connective tissue nevus on the mid- and distal foot with involvement of the first toe. The second toe is absent status postamputation.

arranged perpendicular to the epidermal plane with disarrayed elastic fibers found only in the reticular dermis (McCuaig et al. 2012). Grossly, the CTN of Proteus syndrome has the attribute of deep furrows and ridges, which are reminiscent of the sulci and gyri of the brain, leading to its designation as the cerebriform CTN, or CCTN. The gross appearance of some collagenous CTNs (presumably CCTNs) has also been described as "paving stone nevi" or "plantar fibromatosis," descriptors that we suggest are no longer useful. Notably, this
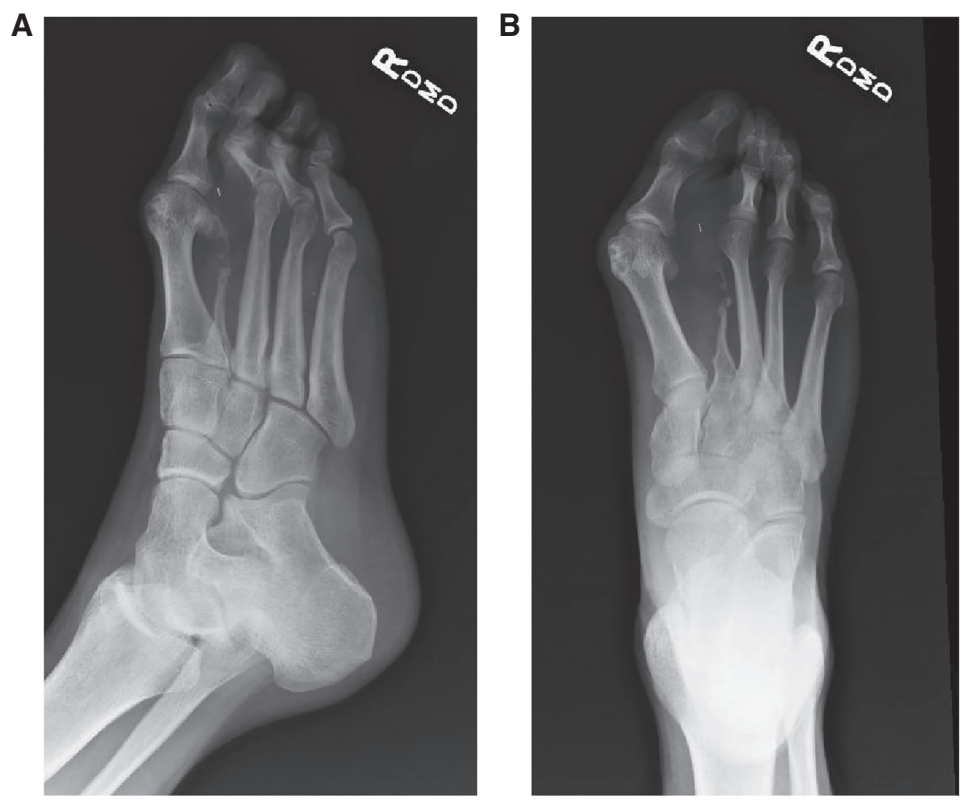

Figure 5. Individual 2 (OG.111). Radiographs of right foot showed absent second toe and metatarsal. A surgical clip is present in the soft tissues of forefoot. (A) Oblique view. (B) AP view. 


\begin{tabular}{|c|c|c|c|c|c|c|c|}
\hline Gene & Chromosome & $\begin{array}{l}\text { HGVS DNA } \\
\text { reference }\end{array}$ & $\begin{array}{l}\text { HGVS protein } \\
\text { reference }\end{array}$ & Variant type & $\begin{array}{l}\text { Predicted } \\
\text { effect }\end{array}$ & $\mathrm{dbSNP/dbVar} \mathrm{ID}$ & Genotype \\
\hline PIK3CA & $\begin{array}{l}\text { Chr 3: } \\
\text { 178952085 } \\
\text { (GRCh37) }\end{array}$ & c. $3140 A>G$ & p.(His1047Arg) & $\begin{array}{l}\text { Single- } \\
\text { nucleotide } \\
\text { substitution }\end{array}$ & Missense & $\begin{array}{l}\text { rs121913279 } \\
\text { SCV000898478.1 }\end{array}$ & $\begin{array}{l}\text { Mosaic (VAF 0.096, } 0.11 \\
0.19 \text {, and } 0.34 \text { in two } \\
\text { samples each from two } \\
\text { individuals) }\end{array}$ \\
\hline
\end{tabular}

attribute is only apparent in the more mature CCTNs of the hand and foot. Early lesions on the soles of the foot appear as papules and nodules that gradually become fully developed CCTNs (Nathan et al. 2018). In addition, CTNs sometime form near the nares or lacrimal puncta where they appear as whitish, firm nodules (see Fig. 4 in Nguyen et al. 2004).

To our knowledge, this is the first demonstration of etiologic heterogeneity of overgrowth associated with a CCTN-two individuals shown to have a mosaic PIK3CA variant from CCTN tissue, instead of the expected AKT1 variant. In individual 1, the CCTN was demonstrated unambiguously by histologic analysis of the lesion, which shows the characteristic dense collagen fibrils of that lesion. Individual 2 has the same lesion on clinical examination, but unfortunately the biopsy was not sent for fixation and embedding. Whether these individuals meet the current clinical diagnostic criteria for Proteus syndrome is debatable. They both clearly meet the general criteria of sporadic occurrence and mosaic distribution of lesions. The progressive general criterion is ambiguous. This attribute has been described in Proteus syndrome as "rapidly progressive and typically occurs at a frighteningly rapid pace" (Biesecker 2006). Most individuals with PS are born without significant asymmetry and the asymmetric overgrowth starts in the 6- to 18-mo age range. The rate of overgrowth is such that affected body parts rapidly become disproportionate (Biesecker 2006). Instead, most of the overgrowth in the two individuals reported here occurred before 18 mo of age. The general criterion of "progressive course" overlaps with the specific criterion in category B, "asymmetric, disproportionate overgrowth." Considering the literal wording, their findings could be interpreted as meeting this criterion. This attribute has been described as "irregular and progressive" to distinguish it from the more common form of overgrowth, which is proportionate and regular or what we have termed "ballooning." In ballooning overgrowth, there is less distortion of the body part, both grossly and radiographically. Indeed, one of the hallmarks of the overgrowth of Proteus syndrome is that the affected bones can become unrecognizably distorted (Biesecker 2006), whereas the skeletal series of the legs and feet in these two individuals showed no significant distortion of the skeletal architecture away from the areas that were operated upon (Figs. 2A,B and 5A,B) when compared to the severe and extensive skeletal abnormalities of a patient with Proteus syndrome (Fig. 6A,B).

\begin{tabular}{ll}
\hline Table 3. Connective tissue nevi of the collagen type \\
\hline Nonheritable & Eruptive collagenoma \\
& Nonfamilial or isolated collagenoma \\
& Proteus syndrome cerebriform connective tissue nevus \\
& PIK3CA-related overgrowth spectrum cerebriform connective tissue nevus (rare) \\
Heritable & Familial collagenoma \\
& Buschke-Ollendorff syndrome \\
& Shagreen patch of tuberous sclerosis \\
& Multiple endocrine neoplasia, Type 1
\end{tabular}

Modified and adapted from McCuaig et al. 2012. 

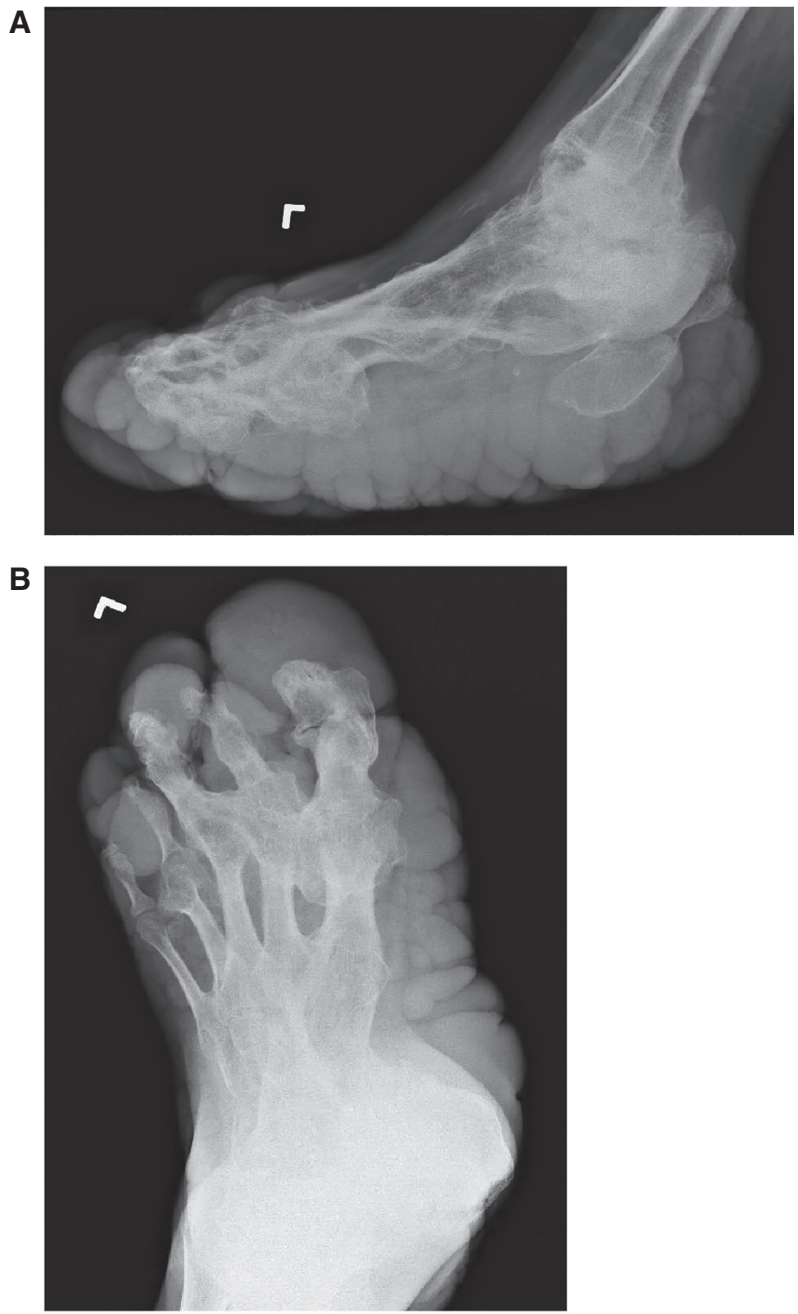

Figure 6. Radiographs of distorting bone lesion in PS. (A) Lateral and (B) AP radiographs of a patient with AKT1 c.49G >A-positive Proteus syndrome. Note the severe, distorted skeletal architecture with major distortion of numerous long and short bones of the foot. Note also the bizarre lateral fusions of the metatarsals. This foot had not been subjected to major orthopedic surgery as had that of the two individuals with PROS reported here.

An individual with a similar presentation was reported recently. The authors (Valentini et al. 2018) described a 57-yr-old man with asymmetric skeletal overgrowth and an overgrowth lesion of the skin and subcutaneous tissue of the foot that was described (correctly, in our opinion) as not to be a CCTN. This lesion lacked the characteristic pseudo-sulci and pseudo-gyri of a CCTN. Histology was not presented, so its identity is unproven, and it is unknown if this is a collagenoma or another form of connective tissue nevus. This individual was found to have the same PIK3CA c.3140G >A variant as the two individuals described above at a VAF of 0.093 . These authors astutely noted that the individual lacked many other features of Proteus syndrome and initially characterized him as having "suspected Proteus syndrome" but rediagnosed him as having PROS following the molecular finding. The two individuals reported here are overall quite similar to that individual with the exception that they had what we assessed on clinical grounds as being a true CCTN, one of which was 
shown histologically to contain increased collagen, oriented perpendicular to the skin surface, and decreased elastic fibers, as observed in CCTN of Proteus syndrome.

A number of individuals have been described with collagenous CTN that were not associated with features of either Proteus syndrome or PROS (Botella-Estrada et al. 1991; Martinez et al. 1994; Altinyazar et al. 2002; Choi et al. 2002; Nico et al. 2003; RodríguezMartin et al. 2007; Nelson and Ruben 2008; McCuaig et al. 2012; Chen et al. 2015). Either these individuals may have a form of Proteus syndrome or PROS that is so anatomically limited as to be unrecognizable as such or CCTNs and CTNs are indeed etiologically heterogeneous.

The Proteus syndrome clinical criteria, strictly applied, are not in conflict with the molecular findings in these individuals. However, we recognize that there is a subjective component of these criteria. There are a number of attributes that make Proteus syndrome generally clinically distinct from PROS. Overall, individuals with Proteus syndrome have a much more aggressive natural history than do individuals with PROS (Biesecker et al. 1999; Biesecker 2001, 2006; Beachkofsky et al. 2010; Sapp et al. 2017). The skeletal manifestations are more distorting in Proteus syndrome than in PROS. Even though PROS is likely to be at least 100 times more common than Proteus syndrome, there are more reports of individuals with Proteus syndrome and tumors than there are reports of individuals with PROS and tumors (Gordon et al. 1995; Biesecker 2005, 2006; Gripp et al. 2016). Given that the denominator for PROS is larger, this suggests (but does not prove) that the risk of tumors is much higher in Proteus than in PROS. Further, we are not aware of myocardial fat overgrowth in individuals with PROS, whereas this is common in Proteus syndrome (Hannoush et al. 2015). Other generalizations could be enumerated, but the point is that although both Proteus syndrome and PROS can display a wide range of severity, the nature and frequency of specific manifestations are distinct in the two syndromes. Therefore, we conclude that it is still valid to consider them distinct clinical entities.

We detected the PIK3CA variant in these individuals in low-passage cultured cells with VAF ranging from 0.09 to 0.34 . There is a concern that culturing cells may inflate the VAF as cell culture may positively select for cells with the variant. This is a critical consideration when one is testing hypotheses of the relationship of the level of variants versus the severity of a particular phenotypic manifestation. Here, we are only asserting a qualitative relationship of PIK3CA- (vs. AKT1-) activating variants to the presence of a CCTN. We did not detect the AKT1 variant, with a conservative VAF sensitivity of 0.005 (although we suspect our threshold is even lower than this). One could hypothesize that we missed a low-VAF AKT1 variant in these individuals. We think this is unlikely as the growth advantage of cell culture ought to apply to both gene variants. As well, we have not seen any sample with both PIK3CA and AKT1 in the hundreds of individuals tested at the $\mathrm{NIH}$ (unpubl.) and are unaware of this observation from discussing cases with several other laboratories. Based on this evidence, we conclude that it is the PIK3CA variant alone that is causing these CCTNs, although we recognize that it is impossible to prove a negative scientific assertion (absence of a low-level mosaic AKT1 variant).

Based on these general considerations and the observation of two individuals with PIK3CA mosaic variants and CCTNs, we suggest that clinicians should be cautious in diagnosing an individual with Proteus syndrome primarily on the basis of a CCTN, absent other convincing manifestations. The CCTN is highly correlated with a molecular diagnosis of Proteus syndrome, but these data reinforce that it is not a pathognomonic sign. Strict application of the diagnostic criteria, especially the three general criteria, is important for accurate diagnosis. As well, these data highlight the growing importance of molecular testing for Proteus syndrome and PROS, which is available clinically. Although such testing does necessitate a biopsy sample, we suggest that this testing can be clinically useful in predicting the natural history of the individual, their risk for tumors, and character of, and risk for, predominantly bony versus fatty overgrowth, among other considerations. These observations raise 
the interesting question as to why CCTN is rare in individuals with PROS. Analogous to the argument above regarding tumor susceptibility, given that PROS is at least $100 \times$ as common as Proteus, CCTN is very rare in PROS, compared to Proteus. We speculate that the pathophysiology of the two disorders is not entirely similar and that the natural history of Proteus (with primarily postnatal growth) and the mechanism of overgrowth in Proteus (which can be either hyperplasia or excess extracellular matrix [ECM]) (Doucet et al. 2016) is subtly distinct from PROS. PROS overgrowth is primarily prenatal and, to our knowledge, entirely hyperplastic (i.e., not attributable to excess ECM). The CCTN is almost entirely composed of dense ECM, primarily collagen, which is associated more with Proteus and AKT1 rather than PROS and PI3K. These speculations should be tested by further experimental work.

As we move toward targeted therapeutics, precise molecular delineation of mosaic overgrowth disorders will be ever more important. Indeed, the observations reported here further support the notion that our field will need to begin shifting from a primarily phenotypic taxonomy of disease to a molecular taxonomy of disease (Institute of Medicine 2011). This is a radical concept and one that many clinicians are likely to find challenging. Our colleagues in oncology have initiated this transition by beginning to shift their diagnosis and management of cancer to an approach that is more based on molecular attributes, rather than phenotype (histology, in this case). Although it is still the case that overall Proteus syndrome is distinct from PROS as a pair of generally distinguishable clinical entities, the overlap is not trivial or arcane. Indeed, we anticipate the identification of individuals whose phenotype is ambiguous (between PROS and Proteus), and we would most definitely manage them based on their molecular findings. There are many challenges inherent in this shift in the fundamental basis of the taxonomy of disease, and we would be wise to carefully observe, document, and discuss the presentation of individuals with disorders who are testing the boundaries of this fascinating and important issue.

\section{METHODS}

Fibroblast cultures were established from punch biopsies of CCTNs. For individual 1, punch biopsies of affected skin were taken from the medial area of the upper heel and the lateral edge of the left foot. For individual 2, fibroblast cultures were established from two punch biopsies of affected skin on the instep of the right foot. DNA was isolated from cultured cells at either passage 2 (individual 1) or passages 2 and 5 (individual 2), using standard extraction methods and genotyped using a custom PCR restriction assay for the PIK3CA c.3140A>G p.(His1047Arg) and the AKT1 c.49G>A p.(Glu17Lys) variants as described in Lindhurst et al. $(2011,2012)$. The lower limit of sensitivity for these assays is $0.5 \%$.

\section{ADDITIONAL INFORMATION}

\section{Data Deposition and Access}

The variant was deposited in ClinVar (https://www.ncbi.nlm.nih.gov/clinvar/) and can be found under accession number SCV000898478.1.

\section{Ethics Statement}

This study was performed under National Institutes of Health $(\mathrm{NIH})$ human subjects research protocol (94-HG-0132). Both participants provided written informed consent and had an opportunity to review this manuscript. 
COLD SPRING HARBOR Molecular Case Studies
PIK3CA and cerebriform connective tissue nevus

\section{Competing Interest Statement}

L.G.B. is a member of the Illumina Medical Ethics Board, receives royalties from Genentech, Inc., receives in-kind research support from ArQule, Inc., and is the deputy editor for this journal.

\section{Referees}

James T. Bennett

Anonymous

Received January 26, 2019; accepted in revised form April 9, 2019.

\section{Acknowledgments}

The authors are deeply indebted to the two individuals for participating in this study. Julia Fekecs provided graphics support.

\section{Author Contributions}

K.M.K.-N. evaluated these individuals in the clinic, J.B.-A. retrieved and evaluated clinical data, M.J.L. oversaw the molecular evaluations and evaluated those data, J.S. generated the molecular data, J.C.S. evaluated clinical data, and T.D. evaluated the individuals in the clinic and biopsied the lesions for molecular testing. All of these authors reviewed and edited the manuscript. L.G.B. designed and oversaw the study and wrote the manuscript.

\section{Funding}

The work described here was supported by the Intramural Research Program of the National Human Genome Research Institute grants ZIA HG200328-14 and ZIA HG200388-06.

\section{REFERENCES}

Altinyazar HC, Kargi E, Gün BD, Koca R, Tekin NS. 2002. Isolated plantar collagenoma: a case report. J Dermatol 29: 508-511. doi:10.1111/j.1346-8138.2002.tb00317.x

Beachkofsky TM, Sapp JC, Biesecker LG, Darling TN. 2010. Progressive overgrowth of the cerebriform connective tissue nevus in patients with Proteus syndrome. J Am Acad Dermatol 63: 799-804. doi:10.1016/ j.jaad.2009.12.012

Biesecker LG. 2001. The multifaceted challenges of Proteus syndrome. JAMA 285: 2240-2243. doi:10.1001/ jama.285.17.2240

Biesecker LG. 2005. Proteus syndrome. In Management of genetic syndromes (ed. Cassidy SB, Allanson JE), pp. 449-456. Wiley, New York.

Biesecker LG. 2006. The challenges of Proteus syndrome: diagnosis and management. Eur J Hum Genet 14: 1151-1157. doi:10.1038/sj.ejhg.5201638

Biesecker LG, Happle R, Mulliken JB, Weksberg R, Graham JM Jr, Viljoen DL, Cohen MM Jr. 1999. Proteus syndrome: diagnostic criteria, differential diagnosis, and patient evaluation. Am J Med Genet 84: 389395. doi:10.1002/(SICI)1096-8628(19990611)84:5<389::AID-AJMG1>3.0.CO;2-O

Botella-Estrada R, Alegre V, Sanmartin O, Ros C, Aliaga A. 1991. Isolated plantar cerebriform collagenoma. Arch Dermatol 127: 1589-1590. doi:10.1001/archderm.1991.01680090155029

Chen J, Chen L, Duan Y, Li D, Dong B. 2015. Cerebriform connective tissue nevus of lumbar. J Dermatol 42: 219-220. doi:10.1111/1346-8138.12735

Choi JC, Lee MW, Chang SE, Choi JH, Sung KJ, Moon KC, Koh JK. 2002. Isolated plantar collagenoma. Br J Dermatol 146: 164-165. doi:10.1046/j.1365-2133.2002.4513_2.x

Doucet ME, Bloomhardt HM, Moroz K, Lindhurst MJ, Biesecker LG. 2016. Lack of mutation-histopathology correlation in a patient with Proteus syndrome. Am J Med Genet A 170: 1422-1432. doi:10.1002/ajmg .a.37612

Gordon PL, Wilroy RS, Lasater OE, Cohen MM Jr. 1995. Neoplasms in Proteus syndrome. Am J Med Genet 57: 74-78. doi:10.1002/ajmg.1320570117

Gripp KW, Baker L, Kandula V, Conard K, Scavina M, Napoli JA, Griffin GC, Thacker M, Knox RG, Clark GR, et al. 2016. Nephroblastomatosis or Wilms tumor in a fourth patient with a somatic PIK3CA mutation. Am J Med Genet A 170: 2559-2569. doi:10.1002/ajmg.a.37758

Hannoush H, Sachdev V, Brofferio A, Arai AE, LaRocca G, Sapp J, Sidenko S, Brenneman C, Biesecker LG, Keppler-Noreuil KM. 2015. Myocardial fat overgrowth in Proteus syndrome. Am J Med Genet A 167A: 103-110. doi:10.1002/ajmg.a.36773

Institute of Medicine. 2011. Toward precision medicine: building a knowledge network for biomedical research and a new taxonomy of disease. National Academies Press, Washington, DC.

Keppler-Noreuil KM, Rios JJ, Parker VE, Semple RK, Lindhurst MJ, Sapp JC, Alomari A, Ezaki M, Dobyns W, Biesecker LG. 2015. PIK3CA-related overgrowth spectrum (PROS): diagnostic and testing eligibility criteria, differential diagnosis, and evaluation. Am J Med Genet A 167A: 287-295. doi:10.1002/ajmg.a.36836

Lindhurst MJ, Sapp JC, Teer JK, Johnston JJ, Finn EM, Peters K, Turner J, Cannons JL, Bick D, Blakemore L, et al. 2011. A mosaic activating mutation in AKT1 associated with the Proteus syndrome. N Engl J Med 365: 611-619. doi:10.1056/NEJMoa1104017 
Lindhurst MJ, Parker VE, Payne F, Sapp JC, Rudge S, Harris J, Witkowski AM, Zhang Q, Groeneveld MP, Scott $\mathrm{CE}$, et al. 2012. Mosaic overgrowth with fibroadipose hyperplasia is caused by somatic activating mutations in PIK3CA. Nat Genet 44: 928-933. doi:10.1038/ng.2332

Martinez W, Arnal P, Capdevila A, Almagro M. 1994. Isolated plantar cerebriform collagenoma. Pediatr Dermatol 1: 84-85. doi:10.1111/j.1525-1470.1994.tb00087.x

McCuaig CC, Vera C, Kokta V, Marcoux D, Hatami A, Thuraisingam T, Marton D, Fortier-Riberdy G, Powell J. 2012. Connective tissue nevi in children: institutional experience and review. J Am Acad Dermatol 67: 890897. doi:10.1016/j.jaad.2012.01.036

Nathan NR, Patel R, Crenshaw MM, Lindhurst MJ, Olsen C, Biesecker LG, Keppler-Noreuil KM, Darling TN. 2018. Pathogenetic insights from quantification of the cerebriform connective tissue nevus in Proteus syndrome. J Am Acad Dermatol 78: 725-732. doi:10.1016/j.jaad.2017.10.018

Nelson AA, Ruben BS. 2008. Isolated plantar collagenoma not associated with Proteus syndrome. J Am Acad Dermatol 58: 497-499. doi:10.1016/j.jaad.2007.03.016

Nguyen D, Turner JT, Olsen C, Biesecker LG, Darling TN. 2004. Cutaneous manifestations of Proteus syndrome: correlations with general clinical severity. Arch Dermatol 140: 947-953. doi:10.1001/archderm .140.8.947

Nico MM, Valente NY, Machado KA. 2003. Isolated plantar collagenoma. Acta Derm Venereol 83: 144. doi:10 $.1080 / 00015550310007571$

Rodríguez-Martin M, Sáez-Rodríguez M, Carnerero-Rodríguez A, de Paz R C, Sidro-Sarto M, Pérez-Robayna N, García-Bustínduy M, Rodríguez-García F, Sánchez R, Díaz-Flores L, et al. 2007. Plantar collagenoma in a karate practitioner. J Eur Acad Dermatol Venereol 21: 247-248. doi:10.1111/j.1468-3083.2006.01805.x

Sapp JC, Hu L, Zhao J, Gruber A, Schwartz B, Ferrari D, Biesecker LG. 2017. Quantifying survival in patients with Proteus syndrome. Genet Med 19: 1376-1379. doi:10.1038/gim.2017.65

Uitto J, Santa Cruz DJ, Eisen AZ. 1980. Connective tissue nevi of the skin. J Am Acad Dermatol 3: 441-461. doi:10.1016/S0190-9622(80)80106-X

Valentini V, Zelli V, Rizzolo P, Silvestri V, Alimandi M, D'Aloia MM, Giustini S, Calvieri S, Richetta AG, Monteleone G, et al. 2018. PIK3CA c.3140A>G mutation in a patient with suspected Proteus Syndrome: a case report. Clin Case Rep 6: 1358-1363. doi:10.1002/ccr3.1546 


\section{COLD SPRING HARBOR Molecular Case Studies}

\section{Molecular heterogeneity of the cerebriform connective tissue nevus in mosaic overgrowth syndromes}

Kim M. Keppler-Noreuil, Jasmine Burton-Akright, Marjorie J. Lindhurst, et al.

Cold Spring Harb Mol Case Stud 2019, 5: a004036

Access the most recent version at doi: $10.1101 / \mathrm{mcs} . a 004036$

License This is a work of the US Government.

Email Alerting Receive free email alerts when new articles cite this article - sign up in the box at the Service top right corner of the article or click here. 